\title{
The Socio-Emotional Adjustment of Learning-Disabled Students Undergoing School Transitions
}

\author{
Zaher Accariya, Mahmood Khalil \\ The College of Sakhnin, Academic College for Teacher Education, Sakhnin, Israel \\ Email: accariya@gmail.com, mahkh@macam.ac.il
}

Received 29 December 2015; accepted 26 January 2016; published 29 January 2016

Copyright (C) 2016 by authors and Scientific Research Publishing Inc.

This work is licensed under the Creative Commons Attribution International License (CC BY).

http://creativecommons.org/licenses/by/4.0/

(c) (i) Open Access

\begin{abstract}
This study examined learning-disabled (LD) students' subjective interpretation of their sociocultural reality during the transition periods into junior high school. LD students are liable to have emotional, psychological and social problems: they are prone to anxiety, depression, and behavioral disorders, as well as feelings of low self-esteem and social isolation. These may lead to genuine crisis during the already difficult transition from elementary school to junior high. Research in the form of in-depth interviews was conducted on a sample of $12 \mathrm{LD}$ adolescent, junior-high students. The findings point to three main concerns of LD adolescents regarding their transition to junior-high: A sense of isolation, a lack of social and adaptation skills, and a poor relationship with teachers. The findings of this study may be useful for planning intervention and prevention programs that provide support and assistance for LD students' adaptation. It is crucial to assist LD students to develop and cultivate social and educational skills during the transition period, thus allowing them to learn how to cope, not only during this crisis period, but with other life situations.
\end{abstract}

\section{Keywords}

Learning-Disabled, Junior High School, Low Self-Esteem, Social Skills, Adolescent Concerns

\section{Introduction}

The various definitions of learning disability indicate that learning-disabled (LD) students are liable to have emotional and social problems (MOECS, 1992, 1996; NJCLD, 1994). Various studies also indicate that LD students may develop psychological and social problems: they are prone to anxiety, depression, and behavioral disorders, as well as feelings of low self-esteem and social isolation (Lufi, Elner, \& Levi, 2004). 
When transitioning from one educational environment to another, most students undergo feelings of loss: they are leaving people and an environment with which they have grown accustomed to and are at ease, and must make the effort to adapt to a new situation. Such transitions may lead to crisis (Sadeh, 1983) since they generate dread, curiosity, and anxiety, and require the individual to adapt to new norms and procedures. The transition from elementary school (grades 1 - 6) to junior high (grades 7 - 9) involves unique and complex coping mechanisms because, alongside the profound changes in the educational framework, the student is also going through the sweeping changes of puberty (Margalit, 2004). This transition is a difficult phase particularly for LD students, one that can lead them to a genuine crisis. With this in mind, it is important to examine the subjective attitudes of LD students entering junior high regarding their emotional and social adaptation into the heterogeneous classroom.

\subsection{What Is Learning Disability?}

A review of the literature reveals various definitions for the term "learning disability", indicating the complex nature of the term, as well as the heterogeneous nature of learning disability (Heiman, 2000; Fletcher, Lyon, Fuchs, \& Barnes, 2004). According to Modlinger (2005), "learning disability" is a generic term that refers to a heterogeneous group of disorders probably originating as a result of a dysfunction of the central nervous system. The dysfunctional behavior may be expressed by the impairment of various abilities, such as speaking, writing, reading, reasoning, attaining and sustaining attentiveness, and developing mathematical skills. The extent of the manifestation of these disorders is unique for each individual.

At present, the definition accepted by the Israeli Ministry of Education is based on "the gap model". According to this model, an individual is defined as LD when, and if, individually given standard tests in reading, mathematics, or writing literacy show significantly lower results than expected for his or her age. In addition, students are defined as LD if their intelligence quotient (IQ) and/or their learning difficulties significantly affect academic achievement and/or everyday activities that require reading, writing, or mathematical skills (MOEC, 2000). Thus, a student is defined as LD when two conditions are met: 1) there is a significant gap between the student's academic achievements and those expected at his/her age level or of his/her class peers; 2) there is a gap between academic achievement and intellectual skill.

Nevertheless, a more up-to-date and accepted definition for LD was published in 2013 in the DSM-V Guide (American Psychiatric Association, Diagnostic and Statistical Manual of Mental Disorders, 5th ed.). It defines learning disability as a neuro-developmental disability with biological factors that lead to the cognitive difficulties experienced by the LD, causing significant impairment in learning or functioning. The DSM-V definition offers some significant innovations, inter alia, expanding the list of criteria for diagnosis, placing stronger focus on both the definition of the disability and on the definition of its severity, abandoning the gap model as the main model for diagnosing learning disorders (which was still adhered to in previous editions), and emphasizing that the disorder continues to affect the individual throughout his lifetime. In addition to these innovations, the latest edition refines exclusion criteria while simultaneously permitting determination of a learning disorder when achievement is observed to be at a lower level than expected, even among individuals with a borderline or elevated IQ.

Although there are no precise, quantitative statistics regarding LD incidence in Israel, accepted estimates suggest that LD students constitute about $10 \%$ - 20\% of the population (Fogel, 1998; Nitzan-Israel, 2013). Similarly, Psychological Consultations Services (2013) estimates that $10 \%$ to $20 \%$ of all students can be considered LD students. With regard to the Arab sector in Israel, reports by the Ministry of Education Margalit Commission (1997) and the Office of the Comptroller (2001) indicated that teachers and parents in the Arab sector were not well informed about the issue of learning disabilities. In recent years, following the recommendations of the Margalit Commission, which recommended, inter alia, raising teacher awareness vis a vis LD student integration, emphasizing the importance of successfully integrating students, and supplying appropriate tools to the teachers, LD awareness in Israeli Arab society has risen, as is especially evident in the increased number of diagnosis referrals to determine eligibility for adjustments in matriculation exams. This increase reflects more focused attention on learning disabilities in Arab society (Margalit \& Efrati, 2001).

\subsection{Adolescence and Its Implications}

American psychologist and educator G. Stanley Hall (1846-1924) was a pioneer in the field of adolescent de- 
velopment. Hall divided human development into four stages: early childhood, childhood, pre-puberty, and adolescence. In 1904, with the publication of his book Adolescence, psychologists began systematically studying this specific period of life. Hall was the first to suggest that adolescence was a major stage in development and that the individual's sense of identity, which began developing previously, reaches maturation during adolescence. This is the stage where character, talent, predispositions, and opinions are defined. Emotionally, the adolescent period is one of stress and turmoil, mainly due to the physical changes associated with puberty (Ziv, 1984).

Erikson (1987) defines an adult as one who has arrived at a defined personal identity, and who is aware of himself, his weaknesses, skills, preferences, and aspirations. Adults are aware of the attitudes and attributes that distinguish them from others and accept themselves for who they are; they have thus developed their own personal identity. Adolescence, therefore, is a significant stage in life since this is the time that an individual's identity is being defined and organized anew as a result of the influence of interdependent interactions between them and society. While parents have the main role in defining the identity of pre-adolescents, during adolescence, teenagers evolve from being dependent on their parents to being independent and forming their own sense of self-identity. Adolescents exhibit less interest in their parents' activities, gradually moving away from them, devoting more time to peer-group activities, and eventually fitting into an egalitarian society. Adolescent psychological maturation naturally includes rebelliousness against parental authority, leading often to parent-teenager conflict. Unpredictable mood swings also add to any distress. During late adolescence, the teenager affirms his independence (Erikson, 1987).

According to Solberg (2007), adolescence has numerous ramifications on the behavioral, emotional, cognitive, psychological, and social levels. Sex hormones secreted during adolescence affect human behavior both directly and indirectly, and studies have shown testosterone to be linked to violent expression, which explains the increase in violence amongst teenage boys, to some extent. Emotional problems have also been shown to be due to the physical and sexual changes during puberty. Studies have shown that during early adolescence (which, incidentally, is concurrent to the transition to junior high), teenagers tend to show displeasure with their appearance, leading to a distorted self-image.

Another area of considerable change is the cognitive one, which stems from the significant changes that take place in adolescent thought processes and moral judgment. Adolescent reasoning is considerably different than a child's, and two subtypes of formal thinking that develop in the adolescent can be distinguished. The first (age 11 - 14 years) is the preparatory subtype, in which formal function is almost complete: the adolescent displays rational-formal thinking but still struggles to systematically explain, express, or defend their decisions. The second (14 years and up) is full formal function: the teenager is able to systematically explain, express, and defend their assertions in a more abstract and sophisticated fashion (Sroufe, Cooper, \& Dehart, 1998). Cognitive changes have important implications on adolescent behavior and their adjustment to their surroundings. At this stage, teenagers are developing the ability to solve problems more effectively, not just in school but in everyday life. They are also developing the ability to relate to others' points of view, something that will improve interpersonal relationships with key people in their lives. Flexible objective-systematic thinking allows adolescents to better cope with stress.

During adolescence, significant changes are also occurring socially. Adolescents tend to spend more time with friends or alone, as opposed to children, who spend more time with family. In addition, adolescent friendships are based on intimacy, trust, and shared interests with a close friend, whereas children's friendships are more often a result of geographic proximity and mutual playtime. The teenager shares feelings and thoughts with his best friend and consults with this friend regarding personal issues (Eisenberg, Neumark-Sztainer, \& Perry, 2003).

\subsection{Adolescent LD Students}

The number of students diagnosed as LD in high school is significantly higher than the number so diagnosed at younger ages (Margalit \& Efrati, 2002), which is due to the biological, cognitive, and social changes that occur at puberty (Margalit \& Tur-Kaspa, 1998). Studies have shown that some LD students with distinct patterns of neuro-cognitive learning impairment also show distinctly different patterns of psychosocial functioning. LD students have difficulty adjusting to social frameworks, functioning in various social situations, dealing with feelings of failure, and delaying gratification. A significant number of LD students exhibit low self-esteem, 
feelings of isolation, and a tendency toward mood swings (Heath, 1996; Margalit, 1998). The decrease in selfimage puts LD adolescent at a high risk for feelings of loneliness, depression, victimization, and chronic shame (Pelletier, 2001; Petti, Volker, Shore, \& Hayman-Abello, 2003).

LD individuals often suffer from low self-esteem and are therefore more likely than others to confer control of their failure or success on a third party. LD adolescents tend to have a lower self-image than other teenagers as they sense that they do not meet others' expectations of them, and they find they are unable to meet their objectives (Shimshoni \& Brenner, 2004). Their low self-image may also be affected by the attitude of those around them, who may perceive and approach them in a way that is more forgiving along with being less challenging and supportive. For example, a study by Clark (1997) showed that teachers tend to exhibit less anger and more sympathy for LD children because they did not expect these children to perform as well in school as the non-LD students. Such attitudes and lack of confidence on the part of a teacher can damage the LD-adolescents' selfesteem and her motivation to learn. It may also influence the other students' attitude to the LD student.

Social skills reflect the capability of teenagers to use social behaviors such as sharing, cooperation, reciprocity, and understanding the other's point of view in a way that is appropriate to a given social situation. Social skills are important for social development, and are an important contribution to an individual's adjustment not only in junior high, but also later in high school, in institutions of higher education, and in the working environment (Hoglund \& Leadbeater, 2004).

Many studies have examined the difficulties that LD students have in developing social skills. While learning disability is primarily associated with a decline in academic achievement, up to 75\% of LD children also exhibit underdeveloped social skills compared to their counterparts (Kavale \& Forness, 1996; Pearl, 1992). As a result, LD children tend to avoid social interaction, leading to fewer opportunities for social contact. This sets up a vicious cycle that prevents them from acquiring appropriate skills and behavior patterns (Bandura, 1977).

Pragmatic communication embraces a broad area that includes knowing when to speak, with whom, for what purpose, and in what manner. Of all the verbal skills, the pragmatic one is the one that has the greatest impact on social skills, and therefore pragmatic skills are paramount to social function. Investigators studying learning disabilities have reported that LD adolescents also have difficulty with pragmatic communication (Modlinger, 2005). LD adolescents struggle to take verbal initiative, such as joining a conversation, greeting peers, or introducing themselves; they also have difficulty describing situations and objects, or providing instructions. LD adolescents tend to ask few questions, especially open questions, and they are less responsive to requests for help or clarification from those around them. The LD adolescent also does not know how to adapt his manner of speaking to suitable his conversation partner and addresses everyone the same way. While a uniform manner of communication might be acceptable when speaking to friends, it comes across as rude and contemptuous when directed to an educator. Because LD adolescents tend to exhibit negativism or antagonism in their conversations (insults, refusals, orders, complaints, etc.), conversation partners may tend to snub or dismiss them (Heiman, 2000).

The difficulties that LD adolescents have in developing social skills can be divided into three key areas (Pearl, 1992):

1) Poor interpersonal communication and behavioral problems. Interpersonal communication is a basic, vital component in cognitive development and friendship. Interaction with peer groups requires selective attention, high levels of memory organization and cognition, social initiative, and active involvement in diverse interpersonal situations (Shores, 1998). LD students, in contrast to other students, exhibit a lower quality of interaction. They exhibit passive communication patterns, low initiative when it comes to suggesting interaction and co-operation with their peers, and a tendency to avoid social interaction out of fear of failure (Asher, 1988).

2) Inefficient social cognition. Social cognition refers to the knowledge and cognitive processes that an individual uses to interact and relate to others. It seems that the cognitive processes that affect academic skills also affect the LD students' social ability (Tur-Kaspa \& Bryan, 1994). LD students do not process and interpret information correctly. They have difficulty in properly interpreting social signals such as tone of voice, facial expression and body language, and in comprehending their place in relation to others. Their planning strategies are faulty and therefore forming interpersonal relationships becomes problematic (Markoski, 1983).

3) Emotional and motivational problems. Mood is an important element of the individual's emotional realm. It affects behavior and the acquisition of social skills. LD adolescents tend to exhibit emotional issues that include extreme mood swings, difficulty expressing feelings, anxiety, and anger. They also have difficulty empathizing with others and often misjudge the mood and emotions of others (Derr, 1986). 
Bruck (1986) described the emotional and motivational difficulties from two different perspectives: in one, emotional difficulties can be considered one of the primary issues of the learning disabled and come about as a result of academic failure; in the other, emotional difficulties are a result of the secondary issues-frustration, lack of self-confidence, aggressiveness, and depression - that arise from social and academic failure. Fear of failure leads to avoiding communication, which generates feelings of helplessness arising from the inability (or lack of confidence) to influence social conditions. The emotional distress prohibits acquisition of social skills, further leading to social withdrawal and reduced motivation to communicate, as well as reinforcing a passive coping pattern and exacerbated feelings of loneliness and depression (Asher, Parkhurst, Hymel, \& Williams, 1990; Reiff \& Gerber, 1992).

Children with learning disabilities often hear words and phrases such as lazy, spoiled, stubborn, distracted, capitulates too easily, too dependent, irresponsible, not interested in anything, and the like. Often, their surroundings punish and rage at them, which increases the cycle of frustration, rage and helplessness (Levin, 2001). As a result, the LD adolescent struggles to find useful models for solving problems or directing his negative feelings, and his frustration may be expressed by avoiding or resisting interactions or events, and through sadness and angry outbursts. His self-image is damaged, and to overcome the confusion, anxiety, rage, and helplessness he feels, he develops defensive patterns of behavior (Levin, 2001).

Social problems can, as stated, lead to loneliness and depression. Studies that explored differences in the sense of isolation among LD students and their non-LD counterparts have indicated that LD students experience solitude at higher levels in all developmental stages, from kindergarten through high school graduation, with especially elevated feelings of loneliness during junior high (Al-Yagon, 2007; Margalit \& Lackaye, 2008). Also, LD adolescents more often reported being in a bad mood and/or feeling depressed (Heath, 1996). Amongst the LD, symptoms of depression were displayed more often among adolescents compared to children, and among girls than boys (Huntington \& Bender, 1993).

In conclusion, lack of social skills has a profound influence on the functioning of the LD student because they are missing the abilities and skills required for adaptive behavior and appropriate social interaction. Difficulties in any of the three key areas that affect these skills-interpersonal, cognitive-social, and emotional—are equally associated in influencing an individual's behavior, and her ability and resources available for coping in a social system. The cognitive struggle affects the collection of behaviors appropriate for understanding the social situation. Any failing in any one of the components affects adaptation, especially during adolescence, when developing social ties is crucial and significant.

\subsection{Transitional Periods during Adolescence}

Transferring into a new learning framework is a common transition during which any student may experience intensified stress or reaction in response to those changes to which he must adapt. However, the move from one class to another, from elementary school to junior high, or from junior high to high school may have a specially profound impact on the LD adolescent and may be accompanied by behavioral problems, a decline in academic achievement, and an increase in anxiety, especially with respect to social issues (acceptance in a peer group) and the need to meet new academic expectations. Such problems may lead the individual to a decrease in self-esteem and an increase in psychological distress (MOEC, 2004).

Several factors may have an impact on the transition itself and how students cope with it, and they can determine how students adapt to their new academic situation. These factors include the student's psychological characteristics (individual capability, coping patterns, individual autonomy level); the student's family situation (economic level, parenting style); and the policies of the new school (requirement levels, amount of social and emotional support) (MOEC, 2004).

The transition from elementary school to junior high is actually a twofold transition: alongside the change in the academic framework is the transition from childhood to puberty, a time of physical, sexual, and cognitive development; consolidation of one's values; and when social relationships_-particularly those with the opposite sex-are formed. Socially, the peer group exerts the greatest influence on the adolescent who, desiring to create her own independent personality, seeks to disconnect from her parents yet remains dependent upon them financially and emotionally (Yanun \& Rodniki, 2003). From an emotional standpoint, adolescence is very complex. Research has shown that the transition to junior high affects the psychosocial attitude of students and may lead to undesirable feelings, such as stress, helplessness, and lack of satisfaction, along with increased symptoms of 
ADHD, such as lack of concentration, hyperactivity, impulsivity, and decreased self-esteem (Langberg et al., 2008; Wigfield \& Eccles, 1994). An adolescent's frustration threshold is low, and extreme outbursts as a result of anxiety and confusion may occur that that may exhibit aggression, emotional upheavals, defiance, and a tendency to exaggerate conflicts. All this occurs alongside the transition to junior high, which begs the opposite: adaptation skills so as to be able to conform to the educational framework.

The Ministry of Education and Culture (2004) recognizes the challenges that are inherent in the transfer from elementary school to junior high and high schools with their significantly different systems. Students must cope psychologically, socially, and emotionally with a myriad of changes: the transition from being "minors" in primary school to being "young people and adolescents" in junior high and high; the change from a relatively intimate system to a large one that includes a much larger student body; a different method of instruction, wherein students move from teacher to teacher every day, each of whom specializes in a specific subject area and has his or her own teaching style. In addition, junior high is usually more achievement-oriented than primary school and requires coping with a curriculum that is higher in standard and broader in content. To exacerbate the trauma, students moving from elementary to junior high are often forced to leave old friends and are faced with having to form new relationships in a heterogeneous classroom.

All the changes described above present even more of a challenge for LD adolescents, who, as stipulated above, are deficient in social skills, have difficulty developing and acquiring skills, find it hard to adjust, and who also may find that, in relation to that of their peers, their puberty is delayed (Spector, 2000). These gaps may embarrass the LD adolescent and accentuate problems (Margalit, 2000). Also, such youth experience the world differently from their non-LD peers, and events that occur around them are perceived as less predictable. LD adolescents may invent erroneous stories to explain their reality, and these will dictate how they interpret present events and how they respond to future ones (Levin, 2001).

The result of the above may mean that any dialogue between LD adolescents and guidance counselors or other contact person who may try to communicate with the student may go awry. The contact person may have difficulty understanding them and will not supply the acceptance and emotional support needed to produce a safe base for the student.

It is clear that the transition from elementary school to junior high is a complex time and is considered one of the most significant periods in a person's psychosocial and socio-emotional development. It challenges every adolescent at an age when he or she is vulnerable to begin with, and presents even more of a challenge to LD teenagers, who are even more sensitive to such challenge.

While many studies have addressed the issues and difficulties that LD students experience during the transitional period from primary to junior high, there have not been many studies that have turned to the students themselves as a source of data regarding feelings and adjustment issues from their own subjective standpoint. The purpose of this study, therefore, was to examine the socio-emotional adjustment of LD students who attend integrated junior high classes from the subjective perspective of the students themselves. This study is innovative and unique, particularly in the Arab sector, which has seen a development in the awareness of the needs of LD students only in recent years, and have a growing realization that not addressing these difficulties may harm the students' chances to realize their potential.

\section{Method}

\subsection{Participants}

In order to examine LD students' subjective interpretation of their socio-cultural reality during the transition periods into junior high school, a sample set was chosen that comprised 12 adolescent students (7 boys, 5 girls) who had been diagnosed as LD and were attending regular classes in a State-run Arab junior high (grades 7, 8 and 9) in one of the largest cities in northern Israel.

\subsection{Research Tools}

The study consisted of face-to-face, in-depth interviews of approximately 45 minutes each that were conducted with each student individually. The interview was semi-structured, and included 7 open questions (see Appendix 1). The content was recorded for later transcription. 


\subsection{The Research Process}

After receiving approval from the school, a meeting was arranged with the school counselor, who located LD students to participate in the study and then coordinated the time and venue for the interviews. Each student received an explanation of the purpose and procedure of the study; and they were informed that data collection was for research purposes only, that their anonymity would be maintained to ensure maximum privacy and confidentiality, and that they could withdraw from the study at any time. The students were asked to confirm their agreement to participate in writing. The students' parents received an information sheet explaining the goal and process of the study and were requested to give their consent in writing regarding their children's participation.

Interviews were conducted in Arabic. They took place in the student counselor's office, during the school day, at times that were coordinated in advance with the students.

\section{Findings}

For the purpose of data analysis, all the statements and descriptions that were deemed pertinent to the topic of the study were extracted from the interviews and given an initial coding whereby all statements pertaining to one topic were gathered together into one category. This initial classification suggested three main categories that pertained to LD students that had transferred from primary school to junior high: 1) the sense of isolation; 2) social skills and their ability to adapt; 3) their relationship with their teachers.

\subsection{Isolation}

A substantial portion of those interviewed reported feelings of loneliness as a result of their transition into junior high. They described feelings of not fitting in, socio-emotional detachment and rejection from their counterparts, and difficulty meeting and bonding with their peers. "Very simply, everything is new to me. There are all kinds of students in the class... and I find it hard to make friends with them. I realize that it's hard to build any relationship with students in the class. Each one comes from a different area and we live far away from each other and only meet at school" (Amir), "It was hard to make new friends in class, so I preferred to go to the classroom where I knew some of the girls. I don't know, maybe it's because I'm fat, but I find it very hard to make new friends” (Rana). Roni’s expressed similar sentiments:

The transition messed up my social life. I'd had friends before, but now they are in a different class. It's not easy to make new friends and to start to get to know people who will understand me and who I will understand. It's boring. I spend most of my time all by myself. In my class, everyone hangs around with the pals he had in grade school. Except for me. It's all very strange to me. And then I think, why should I bother making new friends? I'll be in the very same situation when I'm done with junior high and move to high school. I don’t really like the kids in my class that much. I get the feeling that they are avoiding me... everyone sits together in pairs throughout the year. Except for me. No one suggests sitting beside me.

The students stated that they spend most of their time by themselves, without friends. Some have one friend from elementary school, but it seems that they are spending their time in school without adequate social relations. "I usually am by myself or with one very good friend... She is my neighbor" (Rana). Most of the students expressed feelings of despair, helplessness, and even hatred toward their class and the school: "I hate this school. I don't have any friends and I don't want any. I had friends, but now they're in a different class” (Sayid). "Every day I come home and cry to my mother that I don't want to be in this class" (Oved). "For me, this is a new, strange place. Every morning I wake up feeling that I don't want to go to school, and begin to think of excuses to stay home" (Rana).

\subsection{Social Skills}

The second category that was discerned through the analysis of the interviews was the issue of LD-student social skills. The quality of social skills dictates the behavior that will be expressed in social situations, and having appropriate skills is very important for the individual. An adolescent's social skills are qualified by his teachers' and parents' responses, by the extent of his acceptance within his peer group, and in the amount of adjustment that he shows to be capable of. Academic ability and self-image are also directly correlated to the level of his social acceptance. 
All the students described going through a long, difficult period of adjustment following the move to the new school. This was accompanied by feelings of anxiety. They expressed the need to have some person to rely on, such as a friend from grade school or a caring relative who could act as an anchor during this period. Some of the students stated that, after a period of adjustment, they now have a good relationship with their peers and feel accepted socially. Nevertheless, it is evident from their statements that their current social ties are mostly based on friendships formed earlier in elementary school, with only a few new friends in junior high. "I have two friends. One was in my class in elementary school and the other I met in my new school” (Miryam). "Many students who were in my sixth grade are in my class now, so maybe it’s easier to connect with them" (Manal). "In seventh grade, I liked to spend most of my time by myself, and sometimes I preferred spending time with my friends from elementary school during the breaks. Now, I have a good, close friend in my class who is from my neighborhood" (Maher).

The students' statements emphasized the difficulty they had forming relationships with classmates who were not familiar to them some way: A friend from elementary school, a relative, or someone from the same neighborhood. Students also reported feelings of low efficacy in creating social bonds, such as not knowing how to connect socially and a tendency toward passivity: "I'm not looking for friends, I can manage on my own." (Amir). "The kids in my class tease me and it hurts me. I don't know how to get closer to them" (Rana). "I hate being alone, but I can't do anything about it. They don't want to spend time with me” (Rana).

\subsection{Teacher-Student Relations}

The third category pertained to the relationship between the teachers and the LD students, and their teachers' perception of their social and emotional condition. All students seemed to feel that their teachers ignored them and did not treat them as they treated students who performed better academically: "They only like the good students. They treat them very differently” (Amir). "Not good at all. They don't pay attention to me, as if I'm not in class" (Sa'id). "The teachers treat the gifted students really nicely. I'm sure that if I would be better academically, they would treat me differently" (Rami).

Some students described difficulty in connecting with their teachers. Maher, for example, said, "When I transferred into seventh grade it took me a long time to get along with the students... and also the teachers. It wasn't easy to learn to understand how each and every one of the teachers thought." Students also reported feeling that their teachers did not understand or support them and even belittled them. Statements indicate tangible feelings of alienation toward teachers, and it seems that the students feel that they are misunderstood at school and have no one to talk to. "I feel they don't understand me” (Amir). “They belittle me” (Roni). “They don't understand us the way they should, and they are strict and mean. It is difficult to create and build a relationship with them" (Manal). In addition, it appears from the students' statements that they are not getting their academic needs met by their teachers, and that they feel that the level of instruction is not always adapted to their needs. Thus, students reported that teachers tend to explain the material in a manner that LD students find too difficult and too rapid, and that the students, on their part, refrain from asking questions or expressing their difficulties during the lessons: "They (the teachers) are short-tempered. But there is no need to ask, I have a home tutor, and I ask her. At school the teachers explain the material too quickly” (Anwar). "No, I don't ask for help; I don't want them to know how hard it is for me to learn" (Miryam).

In summary, an analysis of the interviews points to three main concerns that LD adolescents have concerning their transition to junior high, with emphasis on the social-emotional adjustment. Most of the respondents seemed to experience similar negative feelings of loneliness, being misunderstood and not accepted in their new environment, alienation, and feelings of helplessness, all of which influenced them emotionally and socially. It is apparent that LD students have an especially difficult time adjusting to a new school. One consequence of these difficulties was that it induced them to keep quiet in class: they did not participate in social activities, but even more important, they avoided asking questions about educational content that was not clear to them.

\section{Discussion}

During adolescence, teenagers finds themselves in a constant quest to discover themselves, to define themselves in relation to others, and to construct for themselves an identity which includes not only familial elements but also new and original components (Gotlib, 2013). During junior high, adolescents are taking their first steps toward maturity. At puberty, students undergo two major transitions within the educational framework: from ele- 
mentary school to junior high (from sixth grade to seventh grade), and then from junior high to high school (ninth grade to tenth grade). Coping with transition also involves socio-emotional coping. These transitions can be considered crisis transitions for any student (Sadeh, 1983), but they prove especially challenging and difficult for those with learning disabilities.

In the current study, we examined the socio-emotional adjustment of LD students who had undergone the transition from primary to junior high school, from the subjective perspective of the students themselves. The participants, LD adolescents in heterogeneous classrooms, stressed how difficult it is for them to find their place in their new school. Their statements clearly revealed feelings of solitude and social isolation. They also expressed feelings of boredom that arose directly from their isolation, both in class and during breaks, and negative feelings-including despair, helplessness, and frustration - toward their school. This finding agrees with the relevant literature, which indicates that LD students experience higher levels of solitude than their non-LD peers in all developmental stages from kindergarten until high school graduation (Margalit \& Efrati, 2002; Al-Yagon, 2007; Lackaye \& Margalit, 2008).

The respondents described the transition as a stressful and daunting process that disrupted any order they had already created in their lives. A large proportion of them noted that the new school environment was neither welcoming nor supportive. This may provide a possible explanation for the students' sense of loneliness, in accordance with the conjecture that feelings of solitude form, inter alia, on a background of insufficient reinforcement from the social environment (Young, 1982).

The findings of the current study also point to the effect that the social skills of LD adolescents of junior-high age have on their emotional and social adjustment. Studies in the field of socio-emotional functioning have found that students who report feeling lonely also tend to report shyness, low social skills, a lack of mental stability, and a lack of self-confidence. In contrast, those who have some close relationship and thus feel a sense of intimacy, or are part of a coherent social group are less likely to feel lonely (Rokach, 2001). The findings of the current study show that LD students do indeed have difficulty making new friends in junior high, and their few social ties are based on socialization schemas more appropriate for children, such as those based on location (neighbors), family relationship, or on friendships that were already established in the past. This contrasts with close friendships usually formed in adolescence, which are based on intimacy, trust, and shared interests (Eisenberg, Neumark-Sztainer, \& Perry, 2003).

The students also reported that it took them a long time to understand their classmates and their teachers, and to understand what is expected from them. Some clearly expressed that they did not know how to approach classmates to initiate friendship with them; others did not state this directly, but expressed a desire for their fellow classmates to initiate contact. This information is consistent with the findings of Pearl (1992), who found that the social skills of LD students are less than what is expected at their age, and are expressed through poor interpersonal communication, difficulty in initiating social interaction, interaction characterized by passive communication patterns, a lack of initiative to develop connections, and difficulty understanding social situations and the moods, thoughts, and feelings of others.

All the LD students in the study reported having significant academic difficulty. It is possible that this is due to impaired cognitive processes, which not only create problems in social cognition and the acquisition of social skills, but also in acquiring academic skills (Tur-Kaspa \& Bryan, 1994), because the manner of processing and analyzing information is flawed. Our findings also support the conjecture that students who lack social skills will tend to avoid social interactions, resulting in fewer opportunities to form friendships or to improve social skills (Bandura, 1977).

Another important and interesting finding was that all the participants indicated experiencing negative attention from their teachers. They felt that their teachers don't accept them fully, and even more so, they feel rejected and treated differently and less sympathetically compared to students with higher academic achievement. This finding is somewhat in conflict with Clark's findings (1997), which indicted that teachers tend to be less antagonistic and more compassionate toward LD children. It is possible that this difference lies in the differences between the studies: our study examined only the students' (subjective) perceptions, without any regard to those of the teachers, while Clark's research examined the teachers' perceptions, without regard to those of students. The findings of each study may, in fact, be independent of each other. In other words, students might feel a negative attitude on the part of the teachers and a feeling of rejection compared to other, more successful students, while teachers, for their part, may feel that they tend to ease their expectations of LD students and be more forgiving toward them. In this context, it should be noted that LD students often suffer from low self-es- 
teem, and therefore are more likely than others to afford responsibility with regard to their failures and successes to a third party (Shimshoni \& Brenner, 2004); they also tend to incorrectly interpret the attitude and behavior of teachers as a result of their deficiency in social skills and pragmatism (Tur-Kaspa \& Bryan, 1994).

Notwithstanding these possible explanations, importance must still be awarded to the implications stemming from whatever feelings that LD students have regarding their teachers' attitude toward them, as they create a sense of alienation that may undermine the school experience. If the school is perceived as a hostile, critical place, and the adolescent fears that he is not being listened to or understood, the result is that he finds no outlet for the deep frustration stemming from his learning disability. This further intensifies the feelings of isolation that the student must deal with, and because they find it hard to share their sense of loneliness, they are brought to a point of anxiety that can produce paralyzing feelings of helplessness. These factors further affect the social and emotional adjustment of LD adolescents in their new educational framework.

Many studies emphasize the importance that a strong teacher-student relationships has on a student's self-esteem, her motivation for learning, her social and academic success (Kfir, 2009), and even the extent of love and respect she has toward the teachers, school, and the education system as a whole. A teacher's attitudes toward her student, the degree of trust she has in the student, and the relationship that is woven between them significantly influence the students' emotional, academic, and social development. This relationship is even more important in the case of LD students, who may vent their feelings of frustration through behaviors that are unacceptable in school. In fact, a study that examined discipline problems and behavior of students in school found that an attentive, loving and caring teacher who can listen to and is aware of his students' personal problems, can bond with his students and prevent them from misbehaving (Pintrich \& Schunk, 2002).

This study has a number of methodological limitations, mainly due to the sample set. This study involved a very small number of respondents (12 LD students) who live in the same area, go to the same school, come from the same ethnic sector, and have a similar socio-economic status. This precludes the formation of any significant conclusions that may pertain to the adolescent LD student population in general. To formulate more sweeping conclusions requires a larger number of participants of different groups of students at different stages of adolescence. Also, since our student sample was highly homogenous, they do not represent the entire population. To arrive at any conclusions for a broader population requires performing a randomized study among other population sections in different schools and in different areas. In addition, a longitudinal study following the students throughout the period of their acclimation and adjustment to junior high may provide more varied, in-depth information, and provide insight into the adjustment process over a time period, and not only the retrospective view of the student.

\section{Conclusions}

The findings of this study may be useful for education professionals-principals, teachers, educators, educational advisors - especially during the process of planning the various intervention and prevention programs that provide support and assistance for LD students. The study helps to understand in depth the emotional and social processes in LD adolescents in integrated junior-high classrooms, and emphasizes the influence that the teacher can have on the students' transition to junior high and their adaptation to their new educational environment. It is important to be aware of the effects that this transitional period may have on LD students in regular classes, emotionally, academically, and in terms of student-teacher relations.

In addition, the findings of this study may be put to practical use by interpreting them for the field of educational consulting. This study presents facts regarding the LD student's world, and the emotional and social difficulties during the transitional period are clear and must not be ignored. By thoroughly understanding them, educational counseling can support the student and help him cope. The advisor can thus help both the individual students and the school (as a social-organizational system) attain optimal performance and maximize their inner strengths in a supportive, accepting atmosphere, based on the rights of the child.

Finally, it is crucial to assist LD students to develop and cultivate social and educational skills during the transition period, thus allowing them to learn how to cope, not only during this crisis period, but with other life situations. Successful adjustment to junior high provides individuals with a basic adaptation skill that will prove vital throughout their lifetime, and the education system must do its best to help LD students in this process. Successful adaptation not only means academic achievement, but the development of resilience and appropriate understanding of social situations. 


\section{References}

Al-Yagon, M. (2007). Socio-Emotional and Behavioral Adjustment among School-Age Children with Learning Disabilities. The Journal of Special Education, 40, 205-217. http://dx.doi.org/10.1177/00224669070400040201

American Psychiatric Association (2013). Diagnostic and Statistical Manual of Mental Disorders (5th ed.). Washington DC: Author.

Asher, S. R. (1988). Peer Rejection and Loneliness in Childhood. Paper Presented at the Annual Meeting of the American Educational Research Association, New Orleans.

Asher, S. R., Parkhurst, J. T., Hymel, S., \& Williams, G. A. (1990). Peer Rejection and Loneliness in Childhood. In S. R. Asher \& J. D. Cole (Eds.), Peer Rejection in Childhood (pp. 253-273). New York: Cambridge University Press.

Bandura, A. (1977). Self-Efficacy: Toward a Unifying Theory of Behavioral Change. Psychological Review, 84, $191-215$. http://dx.doi.org/10.1037/0033-295X.84.2.191

Bruck, M. (1986). Social and Emotional Adjustments of Learning Disabled Children: A Review of the Issues. In S. J. Ceci (Ed.), Handbook of Cognitive, Social and Neuropsychological Aspects of Learning Disabilities (pp. 361-380). Hillsdale, NJ: Erlbaum.

Clark, M. D. (1997). Teacher Response to Learning Disability: A Test of Attributional Principles. Journal of Learning Disabilities, 30, 69-79. http://dx.doi.org/10.1177/002221949703000106

Derr, A. M. (1986). How Learning Disabled Adolescent Boys Make Moral Judgment. Journal of Learning Disabilities 19, 160-163. http://dx.doi.org/10.1177/002221948601900305

Eisenberg, M. E., Neumark-Sztainer, D., \& Perry, C. L. (2003). Peer Harassment, School Connectedness and Academic Achievement. Journal of School Health, 73, 311-316. http://dx.doi.org/10.1111/j.1746-1561.2003.tb06588.x

Erikson, E. (1987). Zahut Ne'urim u'Mashber [Youth Identity and Crisis]. Tel Aviv: Sifriyat Poalim Publishing. (In Hebrew)

Fletcher, J. M., Lyon, G. R., Fuchs, L. S., \& Barnes, M. A. (2004). Learning Disabilities: From Identification to Intervention. New York: The Guilford Press.

Fogel, S. (1998). Studentim ha'Lokim b'Limidatum b'Mosadot l'Haskalah G'voha [Students Who Are Learning Disabled in Institutions of Higher Education]. Jerusalem: Leshem Organization. (In Hebrew)

Gotlib, D. (2013) Hitmodedut shel mitbagrim im horim [Adolescents Coping with Parents]. (In Hebrew) http://www.tzohar.org.il/?p=2797

Heath, N. L. (1996). The Emotional Domain: Self-Concept and Depression in Children with Learning Disabilities. Advances in Learning and Behavioral Disabilities, 10A, 47-75.

Heiman, T. (2000). Liku’ye Lemida [Learning Disabilities]. Tel Aviv: Open University Press. (In Hebrew)

Hoglund, W. L., \& Leadbeater, B. J. (2004). The Effects of Family, School, and Classroom Ecologies on Changes in Children's Social Competence and Emotional and Behavioral Problems in First Grade. Developmental Psychology, 40, 533-544. http://dx.doi.org/10.1037/0012-1649.40.4.533

Huntington, D. D., \& Bender, W. N. (1993). Adolescents with Learning Disabilities at Risk? Emotional Well-Being, Depression, Suicide. Journal of Learning Disabilities, 28, 59-166. http://dx.doi.org/10.1177/002221949302600303

Kavale, K. A., \& Forness, S. R. (1996). Social Skill Deficits and Learning Disabilities: A Meta-Analysis. Journal of Learning Disabilities, 29, 226-257. http://dx.doi.org/10.1177/002221949602900301

Kfir, D. (2009). Talmid l’ḥayim—Hishtalmuyot l'oreh ha'ḥayim hen aḥad ha’maftehot shel ma'arahet hịuch t'kina [A Student for Life-Life-Long Learning Is One of the Keys to a Proper Educational System]. Panim, 47, 63-71. (In Hebrew)

Lackaye, T. D., \& Margalit, M. (2008). Self-Efficacy, Loneliness, Effort, and Hope: Developmental Differences in the Experiences of Students with Learning Disabilities and Their Non-Learning Disabled Peers at Two Age Groups. Learning Disabilities: A Contemporary Journal, 6, 1-20.

Langberg, J. M., Epstein, J. N., Altaye, M., Molina, B., Arnold, E., \& Vitiello, B. (2008). The Transition to Middle School Is Associated with Changes in the Developmental Trajectory of ADHD Symptomatology in Young Adolescents with ADHD. Journal of Clinical Child and Adolescent Psychology, 37, 651-663. http://dx.doi.org/10.1080/15374410802148095

Levin, G. (2001). Heibetim b’tipul b’ba'ayot hitnahagutiyot, rigshiyot v’hevratiyot shel yiladim liku’ye limida [Facets of Treatment of Behavioral, Emotional and Social Problem of Children with Learning Disabilities]. Talk given at the Conference for Consultational Psychology, Israel. (In Hebrew)

Lufi, D., Elner, I., \& Levi, N. (2004) Ha’araḥat yiḥolet, kishurim kognitivim u’mafyanei ishi’ut shel mitbagrim im liku’ye limida [Assessment of Intellectual Ability, Cognitive Functioning, and Personality Characteristics of Adolescents with Learning Disabilities]. Sugiyot b’hinuch miyuhad v'shikum [Issues in Special Education \& Rehabilitation], 19, 69-82. (In Hebrew) 
Margalit, M. (1998). Loneliness and Coherence among Preschool Children with Learning Disabilities. Journal of Learning Disabilities, 31, 173-180. http://dx.doi.org/10.1177/002221949803100207

Margalit, M. (2000). Lekut L'mida Ba'kitah [Learning Disability in the Classroom]. Tel Aviv: Mofat Institute. (In Hebrew)

Margalit, M. (2004). Heker hatikvah, hama’amatz v’hamotivatsiya b’lekut lemida. [Studying the Hope, Effort and Motivation in Learning Disability]. Lecture. "Make It So I know” Symposium, Tel Aviv, Israel. (In Hebrew)

Margalit, M., \& Efrati, M. (2001). Seker ivhunim v'hatamot l'talmedai ha'hativa ha'elyona ba'alei liku'ye’i limida-Doh pnimi [A Survey of Evaluations and Adjustments for Junior-High School Students with Learning Disabilities-An Internal Report]. Tel Aviv: Tel Aviv University. (In Hebrew)

Margalit, M., \& Efrati, M. (2002). Hatamot b’bhinot l’talmidim ba’alei likuyot limida: skirat hameḥkar v’hashlaḥotav [Adjustments in Examinations for Students with Learning Disabilities: A Review of Research and Its Implications]. Hayeutz hahinuhi, 11, 48-63. (In Hebrew)

Margalit, M., \& Tur-Kaspa, H. (1998). Liku’ye limida: Model nuro-hitpat’huti rav-memadi. [Learning Disabilities: A Multi-Dimensional Neuro-Developmental Model]. Psychologia, 7, 64-76. (In Hebrew)

Markoski, B. D. (1983). Conversational Interactions of the Learning Disabled and Non-Disabled Child. Journal of Learning Disabilities, 16, 606-609. http://dx.doi.org/10.1177/002221948301601009

Ministry of Education and Culture (MOEC) (2000). Memorandum of the CEO, May 2000. (In Hebrew)

Ministry of Education and Culture (MOEC) (2004). Memorandum of the CEO, December 2004. (In Hebrew)

Ministry of Education Margalit Commission (1997). Committee Report. Israel: Ministry of Education Margalit Commission. (In Hebrew)

Ministry of Education, Culture and Sport (MOECS) (1992). Special Memorandum D, 1992. Memorandum of the General Administration, December 1992. (In Hebrew)

Ministry of Education, Culture and Sport (MOECS) (1996). Special Memorandum D, 1996—Kidum hitmodadut im bdidut, kishrei haverut v'thushat koharentiyot. In D. Chen (Ed.), Hahinuch l'kra'at ha'me'ah ha'esrim v'ahad [Education in Anticipation of the 21st Century] (pp. 489-501). Ramot: Tel Aviv University (In Hebrew)

Modlinger, I. (2005). Liku’ye limida shel hasafa ha'ktuvah [Learning Disabilities of Written Language]. (In Hebrew) http://techedu.huji.ac.il/learning/language/language5.html

National Joint Committee on Learning Disabilities (NJCLD) (1994). Learning Disabilities Issues on Definition. In Collective Perspectives on Issues Affecting Learning Disabilities (pp. 61-66). Austin, TX: PRO-ED.

Nitzan-Israel (2013) Mahi lakut limida [What Is Learning Disability]. Midah Miktzoi: Horim v’Yiladim. (In Hebrew) http://www.nitzan-israel.org.il/home/\%D7\%94\%D7\%95\%D7\%A8\%D7\%99\%D7\%9D-\%D7\%95\%D7\%99\%D7\%9C\%D7 \%93\%D7\%99\%D7\%9D/\%D7\%9E\%D7\%99\%D7\%93\%D7\%A2-\%D7\%9E\%D7\%A7\%D7\%A6\%D7\%95\%D7\%A2\%D7 \%99.aspx\#an1

Office of the Comptroller (OC) (2001). State Comptroller's Report. Israel: Office of the Comptroller.

Pearl, R. (1992). Psychosocial Characteristics of Learning Disabled Students. In N. N. Singh, \& I. L. Beale (Eds.), Learning Disabilities: Nature, Theory and Treatment (pp. 96-125). New York: Springer. http://dx.doi.org/10.1007/978-1-4613-9133-3_4

Pelletier, P. M. (2001). NLD and BPPD: Rules for Classification and a Comparison of Psychosocial Subtypes. Dissertation Abstracts International, 61, 5030B.

Petti, V. L., Voelker, S. L., Shore, D. L., \& Hayman-Abello, S. E. (2003). Perception of Nonverbal Emotion Cues by Children with Nonverbal Learning Disabilities. Journal of Developmental and Physical Disabilities, 15, 23-36. http://dx.doi.org/10.1023/A:1021400203453

Pintrich, P. R., \& Schunk, D. H. (2002). Motivation in Education: Theory, Research, and Applications (2nd ed.). Upper Saddle River, NJ: Prentice Hall.

Psychological Consultations Services (of the Israel Ministry of Education) (2013). Sulamot v’havalim [Snakes and Ladders]. Jerusalem: Publication Department of the Ministry of Education. (In Hebrew)

Reiff, H. B., \& Gerber, P. J. (1992). Adults with Learning Disabilities. In N. N. Singh, \& I. L. Beale (Eds.), Learning Disabilities: Nature, Theory and Treatment (pp. 170-198). New York: Springer. http://dx.doi.org/10.1007/978-1-4613-9133-3_6

Rokach, A. (2001). Strategies of Coping with Loneliness throughout the Lifespan. Current Psychology, 20, 3-18. http://dx.doi.org/10.1007/s12144-001-1000-9

Sadeh, S. (1983). Havlei ha’Ma’avar [The Trials of Transition]. Hed Hahinuh, 1, 257-306. (In Hebrew) 
Shimshoni, R., \& Brenner, A. (2004). Miyumanuyot l'midah l’lomdim im likuyot l'midah. [Study Skills for Students with Learning Disabilities]. Hed HaUlpan ha'Hadash, 87, 98-106. (In Hebrew)

Shores, R. L. (1998). Overview of Research on Social Interaction: An Historical and Personal Perspective. Behavioral Disorders, 12, 233-241.

Solberg, S. (2007). Psyhologia shel hayeled hamitbager. [Psychology of the Maturing Child]. Jerusalem: Magnes Press. (In Hebrew)

Spector, N. (2000). Shikum Liku'ye Limida [Rehabilitating Learning Disabilities]. Tel Aviv: Massada Press. (In Hebrew)

Sroufe, A., Cooper, R., \& Dehart, G. (1998). Hitpathut ha’Yeled: Tiv'ah u’Mahalaha [Child Development: Its Nature and Course]. Tel Aviv: Open University Press. (In Hebrew)

Tur-Kaspa, H., \& Bryan, T. (1994). Social Information Processing of Students with Learning Disabilities. Learning Disabilities Research \& Practice, 9, 12-23.

Wigfield, A., \& Eccles, J. S. (1994). Children's Competence Beliefs, Achievement Values, and General Self-Esteem: Change across Elementary and Middle School. Journal of Early Adolescence, 14, 107-138. http://dx.doi.org/10.1177/027243169401400203

Yanun, Y., \& Rodniki, Y. (2003). Hashpa’at ha’aliya l'ḥativat habenaim al haradat hatalmidim v’tokpanutam k’funktzia shel ma'amad hevrati-kalkali. [The Influence of Entering Junior High on Student Anxiety and Aggressiveness as a Function of Socio-Economic Standing]. Iyunim b’ḥinuch, 5, 81-98. (In Hebrew)

Young, J. E. (1982). Loneliness, Depression and Cognitive Therapy: Theory and Application. In L. A. Peplau, \& D. Perlman (Eds.), Loneliness: A Sourcebook of Current Theory, Research and Therapy (pp. 1-18). New York: Wiley.

Ziv, A. (1984). Hitbagrut [Adolescence]. Tel Aviv: Massada Press. (In Hebrew)

\section{Appendix 1: Interview Questions}

1) Tell me about your own emotional and social experiences when you moved from elementary school to junior high.

2) What significance did the transition period from elementary school to junior high have for you?

3) What feelings did you have during the transition?

4) How are your abilities and your social status perceived in your classroom in terms of emotional and social adjustment, and how do you assess this?

5) Describe your feelings about the other students in your class?

6) What do you do during recess?

7) Describe the relationship between you and your teacher. 